\title{
A home-based palliative care pilot project for the patients and families with incurable diseases in Bangladesh
}

\author{
Chowdhury MK ${ }^{a}$, Sarker $\mathbf{M}^{\mathrm{b}}$, Ahmad $\mathrm{N}^{\mathrm{c}}$
}

\begin{abstract}
Background: Home-based palliative care (HPC) is a community-based palliative care approach with various advantages over institutional care like comprehensive care at patient's known comfortable environment. This study aims at describing a pilot HPC program.

Methods: A 3-year pilot project was implemented by Centre for Palliative Care (CPC) of Bangabandhu Sheikh Mujib Medical University (BSMMU), Dhaka, Bangladesh, supported by the Ministry of Education. At the end of the project period the team attempted a survey to capture a picture of HPC recipients, of their suffering and their needs and to assess as to what extent these needs can be met in the best possible way with the present strategy. A total of 34 patients and their caregivers were interviewed over telephone about receiving homecare. An attempt was taken to compare with the patients who used to get conventional care along with an access to the 24/7 telephone care service.
\end{abstract}

Results: A total of 1634 home visits were made to 338 patients, mostly (79.3\%) to 310 cancer patients and covered $0.807 \%$ of estimated population in need of palliative care in Dhaka City Corporation. Pain was the most prevalent symptom and opioid drugs were the most commonly prescribed medication. HPC helped them to remain at their own home where they wanted to be and assisted them taking into account individually tailoring care and enabled them to continue coping.

Conclusions: HPC helped the patients of incurable diseases and their families to avail comprehensive care at home contributing to reduce hospital burden. Enhancement of the care infrastructure will ensure a sustainable provision of palliative care in the domestic environment.

Key words: Bangladesh, incurable diseases, home-based palliative care, palliative care.

(BIRDEM Med J 2021; 11(3): 202-211)

\section{Author information}

a. Mostofa Kamal Chowdhury, Assistant Professor, Department of Palliative Medicine, Centre for Palliative Care, Bangabandhu Sheikh Mujib Medical University (BSMMU), Dhaka, Bangladesh.

b. Mridul Sarker, Coordinator, Home-based Palliative Care, BSMMU, Dhaka, Bangladesh.

c. Nezamuddin Ahmad, Professor (Retd.) and ex-Chairman, Department of Palliative Medicine, Centre for Palliative Care, BSMMU, Dhaka, Bangladesh.

Address of correspondence: Mostofa Kamal Chowdhury, Assistant Professor, Department of Palliative Medicine, Centre for Palliative Care, BSMMU, Dhaka, Bangladesh. Email: mkcadil@yahoo.com

Received: May 23, 2021

Revision received: June 17, 2021

Accepted: June 30, 2021

\section{INTRODUCTION}

The 'Lancet Commission Report' treats palliative care as an essential component of comprehensive care for persons with complex chronic or acute, life-threatening or life-limiting health conditions and can be provided in any health-care setting, including patients' own homes. ${ }^{1}$ Due to rising prevalence of non-communicable diseases (NCDs) and dramatic improvements in life expectancy in recent decades, to meet the subsequent increase in demand of long-term care for chronic conditions, palliative care is gaining significance. ${ }^{2,3}$ Added to this, the age of potential carers is also increasing. An estimated six hundred thousand people in Bangladesh is in need of palliative care but less than $1 \%$ of these 
have access to it. ${ }^{4}$ Moreover Bangladesh is burdened with a huge number of cancer patients $(1,56,775$ new cancer patients in 2020 with 1,08,990 cancer deaths) who constitute the main bulk of demand of palliative care. ${ }^{5}$

Home based palliative care (HPC) is a community-based approach with various advantages over institutional care like comprehensive care at known comfortable environment resulting in increased patient satisfaction, easy access to care, maintainenance of privacy and confidentiality, control of chronic disease, out of pocket expenditure reduction, minimizing repeated hospitalization, engagement of the community and family members in health service. ${ }^{6}$ Some consider dying at home as a more comfortable and dignified experience than dying in a hospital. ${ }^{7}$ Research evidences showed that more than $50 \%$ of patients and caregivers facing advanced illness including cancers, prefer to be cared for and to die at home and hospital death incur costs seven times higher than death at home. ${ }^{8,9}$ It has been demonstrated that most patients in the terminal stages of cancer would benefit from palliative home-care services. ${ }^{10}$

Despite this, there is no home care service policy in current Bangladesh health policy. Isolated few homecare interventions have been developed, mostly in Dhaka, by individual initiative. The Centre for Palliative Care (CPC) in Bangabandhu Sheikh Mujib Medical University (BSMMU) started HPC service in a limited scale in 2008 by benevolent funding from different individuals and organizations. A 3-year pilot project of home based palliative care program by CPC was implemented from June 2015 to May 2018 supported by the Ministry of Education, Bangladesh. This was truly an opportunity to evaluate the effectiveness of this social intervention and address the gaps and lacks in the local research pool on this important aspect. The roadmap set out for home care is incredibly important for organizing such care nationwide along with further development. This study aimed to describe the experiences of this HPC pilot project along with observation of symptom prevalence and provision of care.

\section{METHODS}

The HPC team of CPC consists of Palliative Care Physicians (PCPs), Palliative Care Nurses (PCNs), Palliative Care Assistants (PCAs) and one Home Care Coordinator (HCC). PCAs are the primary health workers trained for six months, dedicated to provide palliative care and support to patients suffering from terminal illnesses such as cancer or other life-limiting health conditions and can work in a wide range of settings including hospitals, hospices or patients' homes. The home care program supervised by PCPs and PCNs run five days a week. The home care is linked to the existing 24/7 telephone service of the CPC. The regularity of care and the level of care depend on the patient's condition and thereby need. At least one visit in a week is attempted for all terminally ill patients being cared for at home and PCAs attend patients more in the last days of life. Nurses are called in to deal with any need for medication or infusion therapies or for any reason when the PCAs feel necessary to seek help.

At the end of the project period, the team attempted a survey to capture a picture of HPC recipients, of their suffering and their needs and to assess as to what extent these needs can be met in the best possible way with the present strategy. Database of the CPC, BSMMU was used to elicit patients' and their caregivers' and PCAs information regarding demography, illness related suffering and other relevant issues. A total of 34 patients and their caregivers were interviewed over telephone about receiving homecare.

In this study, an attempt was taken to compare two groups of patients: Group-I, the study group who availed usual care along with HPC services from the CPC and participants of the Group-II, the control group who used to get conventional care along with an access to the 24/ 7 telephone care service, led by CPC. A basic analysis of the information received over telephone calls from group-II patients or their family members outside Dhaka was an attempt to explore the patients' need, who were not having any direct palliative care service facilities after they leave the center. Prior to the study, the participants were fully informed about the purpose of the research and method of interview, were ensured about the confidentiality of information and right to withdraw from the study and their informed consent was obtained.

\section{RESULTS}

A total of 1634 home visits were made to 338 patients during the project period, out of which, 215 female patients received $1196(73.2 \%)$ home visits. Average duration of home care for a patient was 6 months and $103(40.9 \%)$ patients breathed their last at home (Table I, II). More than sixty percent of Eastern Cooperative Oncology Group (ECOG) Performance Status ${ }^{11}$ evaluated patients belonged to ECOG 4 (bed bound state) (Table II). 
Table I Demography of patients receiving home care $(\mathrm{N}=338)$

\begin{tabular}{|c|c|c|c|c|}
\hline Characteristics & Male & $\%$ & Female & $\%$ \\
\hline Gender & 123 & 36 & 215 & 64 \\
\hline \multicolumn{5}{|l|}{ Age group (years) } \\
\hline$<25$ & 4 & 3.2 & 5 & 2.3 \\
\hline $25-49$ & 29 & 23.6 & 81 & 37.7 \\
\hline $50-64$ & 44 & 35.8 & 69 & 32.1 \\
\hline$>65$ & 46 & 37.4 & 60 & 48.8 \\
\hline \multicolumn{5}{|l|}{ Occupation } \\
\hline Businessman & 32 & 26.2 & - & - \\
\hline Housewife & - & - & 162 & 75 \\
\hline Service holder & 56 & 46 & 43 & 20 \\
\hline Day labor & 13 & 10.6 & - & - \\
\hline Student & 6 & 5 & 4 & 1.9 \\
\hline Others (retired, unemployed) & 15 & 12.2 & 7 & 3.2 \\
\hline \multicolumn{5}{|l|}{ Education } \\
\hline No formal education & 19 & 15 & 32 & 14.9 \\
\hline Primary level $(\mathrm{I}-\mathrm{V})$ & 7 & 5.7 & 38 & 17.6 \\
\hline High school (VI - X) & 12 & 9.8 & 35 & 16.3 \\
\hline SSC/Dakil & 10 & 8.1 & 40 & 18.6 \\
\hline HSC/Alim & 13 & 10.5 & 23 & 10.6 \\
\hline Graduation/Fazil & 48 & 39 & 21 & 9.8 \\
\hline Post-graduation/Kamil & 13 & 10.5 & 25 & 11.6 \\
\hline Not applicable & 1 & 0.8 & 1 & 0.4 \\
\hline
\end{tabular}

\section{Table II Characteristics of home care visits}

Total number of patients receiving home care

$338(100 \%)$

$215(64 \%)$

$123(36 \%)$

$1634(100 \%)$

$438(26.8 \%)$

$1196(73.2 \%)$

- Male

- Female

ECOG Performance Status assessed patients $(n=103)$

- $\quad$ ECOG-3: $>50 \%$ in bed, but not bedbound - 40 (38.9\%) patients

- $\quad$ ECOG-4: Bedbound - 63 (61.1\%) patients

Period of Home Care Service offered

- 1 to 6 months

- More than 6 months

- $\quad<1$ month

Number of visits by the HPC team

- Physician

- Nurse

- PCA

- Coordinator

- Volunteers

Primary caregivers of patients $(\mathrm{N}=338)$

- Family carers

- Spouse - 103 (30.47\%)

- Daughter - 67 (19.82\%)

- Son - 64 (18.93\%)

- Mother - 24

- Siblings - 13

- Father - 3

- Relatives

- Others

- Unknown
133 (36\%) home visits $232(64 \%)$ home visits

$$
\begin{gathered}
58 \% \\
27 \% \\
15 \% \\
\\
342 \\
387 \\
1584 \\
46 \\
93
\end{gathered}
$$

$274(81 \%)$ 
Within this 3 year service period, the HPC team was able to cover only $0.807 \%$ of estimated population in need of palliative care in Dhaka City Corporation (Table III). Among the 9 thanas, highest number of home care visit was provided at Mirpur area (Figure 1).

Most of the home care (79.3\%) was provided to 310 patients diagnosed with cancer, whereas cerebrovascular disease was the predominant among nonmalignant patients (8\%). It can be noted that female patients with breast malignancies (32\%) and male patients with gastro-intestinal tract malignancies (38\%) were the foremost home care consumers (Table IV). Pain was the most prevalent symptom (Table $\mathrm{V}$ ) and opioid drugs were most commonly prescribed medication (Table VI \& Figure 2) beside skill based care or tasks offered by HPC team in each home visit (Table VII).

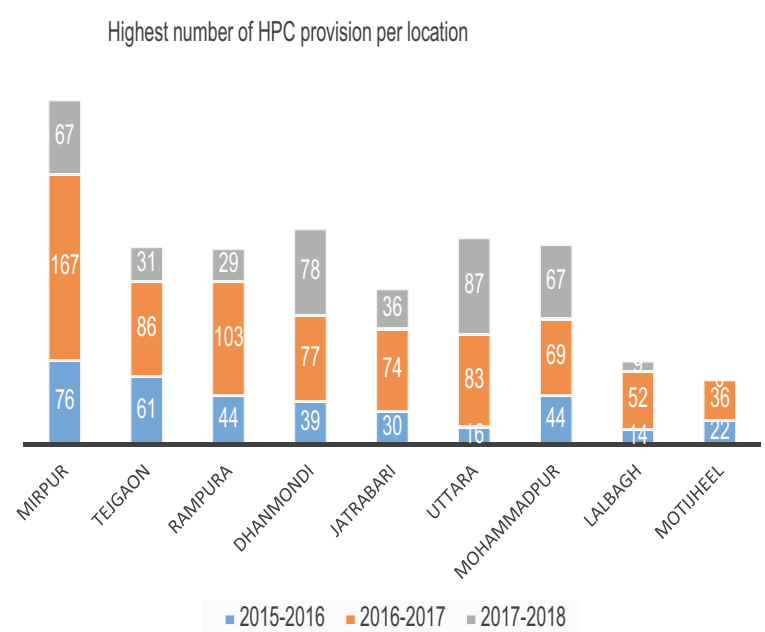

Figure 1 Highest number of HPC provision per location

Table III HPC provided in Dhaka City Corporation

\begin{tabular}{lccccc}
\hline Division & $\begin{array}{c}\text { Area } \\
\text { (sq. km) }\end{array}$ & Population & $\begin{array}{c}\text { Estimated Population } \\
\text { Size in need of } \\
\text { Palliative Care }\end{array}$ & $\begin{array}{c}\text { Population } \\
\text { reached } \\
\text { by HC team }\end{array}$ & $\begin{array}{c}\text { \% of population in } \\
\text { need of PC reached } \\
\text { by the HC team }\end{array}$ \\
\hline North & 82.638 & 3957302 & 11872 & 338 & $0.807 \%$ \\
South & 150 & 10000000 & 30000 & & \\
\hline
\end{tabular}

\section{Table IV Disease profile of patients}

\begin{tabular}{lccc}
\hline Disease & Male & Female & All patients (\%) \\
& $(\%)$ & $(\%)$ & (Only malignancy) \\
\hline
\end{tabular}

Malignant

\begin{tabular}{lccc} 
- GI tract & 38 & 20 & 30 \\
· Breast & - & 32 & 22 \\
- Gynaecological & - & 18 & 13 \\
- Thoracic & 18 & 6 & 11 \\
- Genito-urinary & 11 & 3 & 7 \\
- Head \& neck & 10 & 5 & 5 \\
- Unknown primary & 5 & 2 & 3 \\
- Others & 12 & 4 & 9 \\
Non-malignant & 6 & 10 & - \\
\hline
\end{tabular}

Table V Common symptoms of patients reported by the PCAs during visits

\begin{tabular}{lcc}
\hline Physical symptoms & Frequency & Percentage \\
\hline Pain & 621 & 38 \\
Loss of appetite & 274 & 16.8 \\
Weakness & 252 & 15.4 \\
Swelling & 250 & 15.3 \\
Bed sore and malignant wound & 240 & 14.7 \\
Constipation & 216 & 13.2 \\
Lymphedema & 216 & 13.2 \\
Vomiting & 119 & 7.3 \\
Sore mouth & 111 & 6.8 \\
Cough & 106 & 6.5 \\
Sleeplessness & 101 & 6.2 \\
\hline
\end{tabular}


Table VI Common drugs prescribed at home visit

\begin{tabular}{lcc}
\hline Common Drugs & $\begin{array}{c}\text { Number of } \\
\text { home visits }\end{array}$ & $\begin{array}{c}\text { Percentage } \\
\text { of total }\end{array}$ \\
Prescribed at Home & (n=1634)
\end{tabular}

Opioids

$(\mathrm{n}=1634) \quad$ home visits

- Morphine $(79 \%)$

- Tramadol $(19 \%)$

- $\operatorname{Other}(2 \%)$

Laxatives

Antimicrobial

Adjuvent analgesics

Paracetamol

Antiemetics

Oral rehydration solutions

103

6.30

(ORS)

Antiulcerants

Nebulization

Nonsteroidal anti-inflammatory

drugs (NSAIDs)

Mutivitamins/Minerals/Calcium 26

/Zinc/Hormonal drugs

$\begin{array}{lll}\text { Antitussive } & 16 & 0.98\end{array}$

Diuretics

Antithrombolytics

Others
5.26

4.41

4.41

3.18

2.75

2.20

1.90

1.84

1.65

1.59

$13 \quad 0.80$

$13 \quad 0.80$

$27 \quad 1.65$

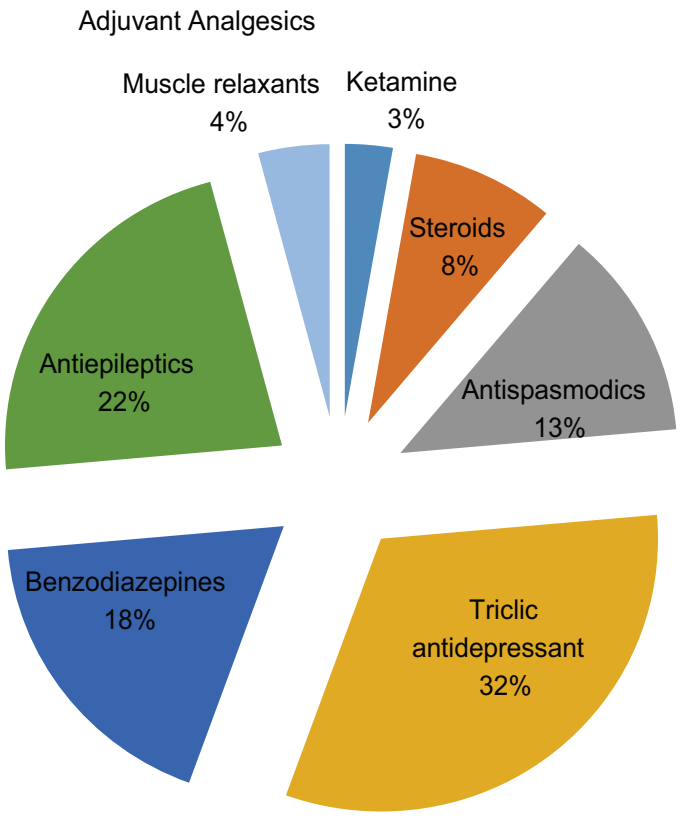

Figure 2 Different types of adjuvant analgesics prescribed by physician

Table VII Common skill based care or tasks offered by HPC team in each home visit

Checking the vital signs of patients on request by the family members or often by the patients

$50.7 \%$

Assistance in taking personal care

$22.8 \%$

Assisted in passive exercise and physiotherapy

$17.1 \%$

Established communication with the patient and their family members regarding their queries

$15 \%$

Cancer wound care and/or bed sore management

$14.7 \%$

Supervised the patient's medicine with assistance in medicine administration

$14.3 \%$

Lymphedema management

$13.6 \%$

During this project period, HPC team could not provide scheduled home care to 64 patients on different occasions even though all the visits were preplanned after consultation with the family members (Table VIII).
An estimation revealed that average cost per patient per year may be 2959 taka (approx.) of which 37\% was spent for salaries of the staffs involved. 
Table VIII Reasons behind not providing home visits ( $\mathrm{n}=64$ )

\begin{tabular}{lcc}
\hline Reasons & Number of home visits & Percentage \\
\hline - Shortage of time & 12 & 18.8 \\
- Patient was not at home & 11 & 17.2 \\
- Disaster (flood) & 7 & 10.9 \\
- Sudden illness of team member & 6 & 9.4 \\
- Went to hospital for acute care & 5 & 7.8 \\
- Transportation maintenance works & 5 & 7.8 \\
- Road construction obstacles & 5 & 7.8 \\
- Call not received by patient or caregiver & 4 & 6.3 \\
- Death of patient before availing home care & 4 & 6.3 \\
- Patient asked the team to switch schedule & 3 & 4.7 \\
- Moved to village/different area & 2 & 3.1 \\
\hline
\end{tabular}

Around $4 \%$ of the patients had huge sufferings at the end of life as mentioned by the family members during the bereavement visit. Among those, severe breathlessness, anxiety, incontinence and pain were documented (Figure 3). The most frequent reason (35\% of total calls) to contact $24 / 7$ telephone consultation service was medicine related issues, mostly regarding morphine and other essential palliative medicines. An attempt had been made to compare symptoms profile (Table IX) and other few findings of two groups (Table X).
Sufferings at End Of Life (EOL)

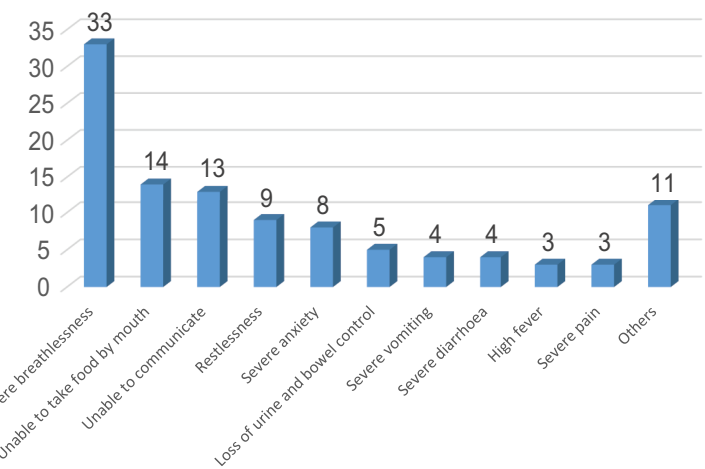

Figure 3 Documented syrmptoffivs in EOL as described by bereaved families

Table IX Comparison of symptom profile between two groups

\begin{tabular}{lcclcc} 
Physical & \multicolumn{2}{c}{ Group- 1 } & \multicolumn{2}{c}{ Group- 2 } \\
Symptoms & $\begin{array}{c}\text { Frequency } \\
\text { of home visits }\end{array}$ & $\begin{array}{c}\text { Percentage } \\
(\%)\end{array}$ & $\begin{array}{l}\text { Physical } \\
\text { Symptoms }\end{array}$ & $\begin{array}{c}\text { Number of } \\
\text { telephone calls }\end{array}$ & $\begin{array}{c}\text { Percentage } \\
(\%)\end{array}$ \\
\hline Pain & 621 & 38 & Pain & 357 & 24 \\
Loss of appetite & 274 & 16.8 & Vomiting & 131 & 8.8 \\
Weakness & 252 & 15.4 & Swelling & 104 & 7 \\
Swelling & 250 & 15.3 & Constipation & 103 & 6.9 \\
Bed sore and malignant wound & 240 & 14.7 & Weakness & 63 & 4.2 \\
Constipation & 216 & 13.2 & Loss of appetite & 61 & 4.1 \\
Lymphedema & 216 & 13.2 & Fever & 57 & 3.8 \\
Vomiting & 119 & 7.3 & Breathlessness & 55 & 3.7 \\
Sore mouth & 111 & 6.8 & Urinary problems & 50 & 3.4 \\
Cough & 106 & 6.5 & Cough & 49 & 3.3 \\
Sleeplessness & 101 & 6.2 & Restlessness & 25 & 1.6 \\
\hline
\end{tabular}


Table $\mathbf{X}$ Highlighting points between study and control group

\section{Group-I: Usual care with home care service (total 338 patients)}

- 1634 home visits to 338 patients.

- $64 \%$ of female patients have got total $73.2 \%$ of home visits, whereas, $36 \%$ male patients got only $26.8 \%$ home visits.

- Most of the informal caregiver at home was family members (81\%), among them $24.4 \%$ daughter and $23.3 \%$ son.

- Mean age of the patients was 56 years; (Range: 1 to 97 years).

- 1 patient got maximum 47 home visits

- Average number of home visit was 5 per patient.

- 201 (59.5\%) patients complain about pain during 621 (38\%) home visits.

- PCAs were the primary level care provider $(97 \%$ visits).
Group-II: Usual care with 24/7 telephone consultation service (Total 379 patients)

- 1482 callS from 379 patient

- $835(56.3 \%)$ calls were for female patients, whereas, 647 (43.7\%) calls for male patients

- $1279(86.3 \%)$ calls were made by family members $489(38.2 \%)$ by patient's son, 231 (18\%) by patient's daughter.

- Mean age of the patients was 47 years (Range: 2.5 to 105 years).

- Maximum 62 calls came from one patientü Average number of calls per patient was 4 .

- In case of physical symptoms, 357 (24\%) call came regarding pain.

- All calls were attended by palliative care physician and mainly pharmacological suggestions were given in response to $835(56.3 \%)$ calls.
Qualitative content analysis part revealed that patients and their caregivers reported the impact and value of each of the components of the service. HPC helped them to remain at their own home, where they wanted to be. It assisted them taking account individually tailoring care and enabled them to continue coping. Rapid access to HPC along with telephone service suggested contributing to reduce hospital admission, unnecessary waiting time at the hospital outdoor or private practitioner's chamber. Caregivers perceived that the additional individual support given by this service contributed to reduce their stress regarding many issues like paying children education, regular wound care, physiotherapy, cost of unnecessary medicines, physicians fee, transport cost etc.

\section{DISCUSSION}

Increasing demand to establish suitable, locally pertinent, feasible and effective palliative care for all, irrespective of disease, place of care and geographical region is a real challenge in upcoming days. ${ }^{12}$ Home care has been promoted in many countries, especially those in which health-care services are overburdened. ${ }^{13}$

Palliative Medicine is yet to find its place in main stream health care provision of Bangladesh. Whatever initiatives are being taken, remain patchy and isolated putting the country in ' $3 a$ ' category by 'Global atlas of Palliative Care' ${ }^{14}$ Consequently, HPC approach remains almost an unknown service provision. Since the inception of palliative care service in the then only medical university of the country in 2007, the initiative has been accompanied by a home care provision in a patchy skeleton level supported by individual and philanthropic donation. This project is the first attempt to organize and prepare a base line observation for further systemic evaluation of the first HPC service of the country.

Female (64\%) were the predominant among the care receipients corresponding with the 3-year study at one hospice and palliative care unit of Nigeria ${ }^{15}$ and the Palliative Care Program at Kaiser Permanente TriCentral Service Area. ${ }^{16}$ In Bangladesh, the female being deprived, neglected and sometimes due to social and cultural barrier brought usually less to hospital. They feel comfortable at home, possibly therefore, the proportion of female home care is higher than male.

HPC visits had been continued for 1-6 months for majority (58\%) of patients, and $>6$ months for $27 \%$ patients, which differs from the Korean study in 2009 with the numbers $38 \%$ and $27 \%$ respectively. ${ }^{17}$ Average duration of providing care by HPC team was 6 months 
with a minimum for 5 days. In a 2-year study to evaluate the effectiveness of a palliative program, mean days on the service was found 102 days ${ }^{16}$ whereas mean duration of service received was 286 days in a Nigerian study. ${ }^{15}$ In a country like Bangladesh, where palliative care is still an unknown subject, the patients are referred and enrolled into the service at advanced stages of their illness. Only few of them become able to continue home care for long time; hence the mean duration is also lower than few other countries.

In HPC conducted by CPC, most visits were done by PCAs; whereas, in Kerala among health professionals, nurses provided more home visits than doctors. ${ }^{18}$ Among 338 patients, $81 \%$ had family members as primary caregiver. Among them the majority were spouse $(30.47 \%)$ followed by son and daughter similar to the Kerala findings. ${ }^{18}$

Within this 3 year service period, the HPC team was able to cover only 9 thanas out of 46 and $0.807 \%$ of estimated population in need of palliative care in Dhaka City Corporation. Limited resource and lack of logistic support are the main factor behind this. Moreover, this is true that only Dhaka city has the provision of palliative care throughout the whole country. These numbers indicate the urgency to look into the matter to meet the crying need.

Over three-fifth of patients (61.1\%) belonging to ECOG 4 (bed bound) state received 232 (64\%) of the evaluated home visits in this setting. Bedridden patients were cared by palliative care team at least once in every week with more frequent visits at last days of life. Bedridden and homebound cancer patients benefitted by palliative care feel respected and cared for and express feeling important and valued as people. Most home care visits (79.3\%) were provided to $310(92 \%)$ patients diagnosed with cancer similar to California. ${ }^{16}$ Bangladesh has more than 1 million patients with cancer at any top of time and about a million suffer from other incurable diseases i.e. progressive neurological, cardiac and respiratory diseases and acquired immunodeficiency syndrome (AIDs) etc. who may in need of palliative care. ${ }^{19} \mathrm{~A}$ crosssectional survey study in Dhaka city in 2016 showed that $78 \%$ of young adults assumed that palliative care only deals with cancer patients! ${ }^{20}$ This concept is not very much uncommon even among the health professionals. As a result at present most of the referred patients are from malignancy, contributing to the cancer patients attaining maximum portion of palliative care in Bangladesh. We expect the disease spectrum to gradually expand to include other conditions requiring long-term care in future like changing dynamics of palliative care programme in Kerala of India. ${ }^{21}$ Female patients with breast malignancies and male patients with GI tract malignancies were the foremost home care consumers similar to Nigeria. ${ }^{15}$

The HPC involved layered team visits but predominantly provided by the PCAs (97\%) under indirect and direct supervision from others. The support is extended to patients' families who are also facing the dreaded prospect of the imminent death of their loved one. One of the main purposes of initiating HPC was to assist the main carers to empower the family carers both in terms of how to take care of their beloved ones rationally and logically as well as to enable them to not feel abandoned in the society. The PCAs, supervised by nurses provided care and support to patients; such as assisting in taking personal care, assistance in passive exercise and physiotherapy, care of cancer wound and bed sores and lymphedema management. Doctors paid attention to any new physical symptoms along with psychosocial issues and took steps accordingly.

HPC team found gap in family understanding of prognosis and outcome of their patient and tried to minimize it by establishing open communication (15\%) mostly with their family members. Very frequent queries made to HPC team were further concern about oncological or curative treatment options, about services of CPC, query about morphine and further need to consult with general physicians. The team felt the necessity to assure the patients and their family members that the team is always with them and they can consult with palliative care physician either in OPD service or through 24/7 telephone consultation service.

Pain was the most prevalent symptom documented similar to Nigeria. ${ }^{15}$ Opioids were most commonly prescribed by physicians following the WHO analgesic ladder; especially morphine. For neuropathic pain control amitriptylines (TCA) was often used as adjuvant analgesics for its easy availability, cheaper price and good efficacy.

In spite of preplanning, the HPC team failed to provide scheduled home care on different occasions. Sometimes 
there was shortage of time due to spending more time for providing care at preceding visit or heavy traffic of the busy capital city. Occasionally patient was not present at home, switched schedule or moved to hospital for acute care even after confirming home care visit. Due to good coordination of team members the system loss was managed to keep under 3.9\%.

HPC helped to reduce the symptom burden of patients as well as their families of advanced illness; which played an important role in subsiding grief for bereaved family members. A 'good death' in a developing country occurs when the dying person is being cared for at home, is free from pain or other distressing symptoms, feels no stigma, is at peace and has their basic needs met without feeling dependent on others. ${ }^{16,22}$ Forty one percent of the expired patients breathed their last at home. At bereavement visit family members of deceased patients expressed their gratitude for HPC. Few patients had huge sufferings at the end of life which were distressful for the family even after all attempts for minimizing agony.

The 24/7 telephone consultation service helped the patients and their families to keep in touch with the team in need and did not let them to feel helpless in emergency situation. Advices provided over telephone saved the families to come to hospital for minor queries and solved medicine related issues, mostly regarding morphine and other essential palliative medicines. Sensible advices to attend the out patient department (OPD) for follow-up and to get admitted into In Patient Department (IPD) for symptoms management helped the families to take timely decisions.

An attempt to draw comparison between home care receiving group and the usual palliative care receiving group revealed similarities like pain as the mostly complained physical symptom and female predominance in seeking medical attention in both groups. The content of the interviews were thoroughly analyzed with focus on the meaning of the informant's sayings. The analyses were mostly reflective of the satisfaction with the service. HPC provided respite care to the caregivers, reduced their burden of monotonous caregiving for long term, abated repeated hospital admissions, consultations and out of pocket expenditures and cared for the value of lives of dying patients with boundless sufferings. Training provided by the team members helped to deliver fruitful care to their loved ones. 24 hour access to telephone consultation never let them feel helpless. Even after the demise of the patient the team was there for bereavement support. HPC was a new cornerstone of health service in addition to the traditional institutional health care system.

\section{Conclusion}

An effective and affordable home based service can have a positive impact on the health and social status of patients, families and the community. However, there are challenges in implementing home care, particularly in developing countries. The national guidelines on HPC should be rolled out to standardize delivery. The results reflect the appraisal that there is considerable room for improvement in the satisfaction with home care by the CPC team to terminally ill cancer or other patients. Enhancement of the care infrastructure is aprerequisite for proximity of care, continuity of care and consequently a sustainable provision of palliative care in the domestic environment.

Authors' contribution: All authors contributed in concept design, literature search, manuscript preparation, editing and review.

Conflicts of interest: Nothing to declare.

Funding: The Ministry of Education, Bangladesh through Bangladesh Bureau of Educational information and Statistics (BANBEIS).

Acknowledgement: We acknowledge the contribution of all of members of the home care service provider team and the patients who received the service.

\section{REFERENCES}

1. Knaul FM, Farmer PE, Krakauer EL, De Lima L, Bhadelia A, Jiang Kwete $\mathrm{X}$ et al. Alleviating the access abyss in palliative care and pain relief-an imperative of universal health coverage: the Lancet Commission report. Lancet 2018;391(10128):1391-1454.

2. Murray CJ, Lopez AD. Mortality by cause for eight regions of the world: global burden of disease study. Lancet 1997;349:1269-76.

3. Davies E. What are the palliative care needs of older people and how might they be met? Health Evidence Network report. Copenhagen: WHO Regional Office for Europe, Available from: www.euro.who.int/__data/assets/ pdf_file/0006/74688/ E83747.pdf. Accessed on 29 January 2021 . 
4. Assessment of palliative care in Bangladesh' conducted by the Centre for Palliative Care in collaboration with and supported by the National Institute of Population Research and Training (NIPORT) (2014).

5. WHO. Bangladesh fact sheet (Source: Globocan 2020). https://gco.iarc.fr/today/data/factsheets/populations/50bangladesh-fact-sheets.pdf

6. World Health Organization. (ý2016)ý. Planning and implementing palliative care services: a guide for programme managers. World Health Organization. https:/ /apps.who.int/iris/handle/10665/250584.

7. Hudson P. Home-based support for palliative care families: challenges and recommendations. Med J Aust 2003; 179: S35-S37.

8. Kodjak, A. (2016). Dying in a hospital means more procedures, tests, and costs. National Public Radio. http:/ /www.npr.org/sections/health-J. Galiana and W. A. Haseltine shots/2016/06/15/481992191/dying-in-ahospital-means-more procedures-tests-and-costs. Accessed on 29 January 2021.

9. Higginson IJ, Sen-Gupta GJA: Place of care in advanced cancer: a qualitative systematic literature review of patient preferences. J Palliat Med 2000;3(3):287-300.

10. Riolfi M, Buja A, Zanardo C, Marangon CF, Manno P, Baldo V. Effectiveness of palliative home-care services in reducing hospital admissions and determinants of hospitalization for terminally ill patients followed up by a palliative home-care team: a retrospective cohort study. Palliat Med 2014;28(5):403-11.

11. ECOG-ACRIN Cancer Research Group. ECOG Performance Status. Available from: https://ecogacrin.org/resources/ecog-performance-status. Accessed on 29 January 2021
12. Harding R, Higginson IJ. Inclusion of end-of-life care in the global health agenda. Lancet Glob Health 2014;2:375-6.

13. Young $\mathrm{T}$, Busgeeth $\mathrm{K}$. Home-based care for reducing morbidity and mortality in people infected with HIV/ AIDS. Cochrane Database Syst Rev 2010;(1):CD005417.

14. Connor S, Sepulveda C, editors. The Global Atlas of Palliative Care at the End of Life. $1^{\text {st }}$ ed. Worldwide Hospice Palliative Care Alliance, World Health Organization; 2014.

15. Omoyeni NE, Soyannwo OA, Aikomo OO, Iken OF. Homebased palliative care for adult cancer patients in Ibadan a three year review. ecancer 2014;8:490.

16. Brumley RD, Enguidanos S, Cherin DA. Effectiveness of a home-based palliative care program for end-of-life. J Palliat Med 2003 Oct;6(5):715-24.

17. Kim SH, Chung BY, Yu Xu. Evaluation of a Home-Based Hospice and Palliative Care Program in a Community Health Center in Korea. Asian Nursing Research 2009;3(1):24-30.

18. Philip RR, Philip S, Tripathy JP, Manim A. Twenty years of home-based palliative care in Malappuram, Kerala, India: a descriptive study of patients and their care-givers. BMC Palliative Care 2018;17:26.

19. Mahmudur Rahman AHM, Reyadul-Ferdous Md. Various Aspects of Palliative Care in Bangladesh. Arch Cancer Res 2016, 4:2.

20. Rahman AHMM, Khan HA. Fundamental perceptions about palliative care among young generations living in Dhaka city, Bangladesh: A short survey, Progress in Palliative Care 2017;25(3):121-5.

21. Kumar S, Numpeli M. Neighborhood network in palliative care. Indian J Palliat Care 2005;11:6-9.

22. Sepulveda C, Habiyambere V, Amandua J, Borok M, Kikule E, Mudanga B et al. Quality care at the end of life in Africa. BMJ. 